\title{
Views of University's Top Management Leaders on University-Community Engagement
}

\author{
Aida Suraya Md.Yunus a, Norzaini Azman ${ }^{\text {b }}$, Shukran Abdul Rahman ${ }^{\mathrm{c}}$ \\ ${ }^{a}$ Universiti Putra Malaysia, 43400 Serdang, Selangor, Malaysia \\ ${ }^{\text {b} U n i v e r s i t i ~ K e b a n g s a a n ~ M a l a y s i a, ~} 43650$ Bangi, Selangor, Malaysia. \\ ${ }^{c}$ International Islamic University Malaysia, P.O. Box 10, 50728 Kuala Lumpur, Malaysia. \\ Corresponding e-mail: aida@upm.edu.my
}

\begin{abstract}
University-community engagement (UCE) activities may be side-lined by academics due to the greater emphasis given to research, publication and teaching in promotion and yearly appraisal. Thus, communities close to a university may not receive any benefits from the existence of a university in their larger neighbourhood. UCE is described by Carnegie Foundation for Advancement of Teaching as the collaboration between higher education institutions (HEIs) and their larger communities (local, regional or state, national, and global) for the mutually beneficial exchange of knowledge and resources in a context of partnership and reciprocity. Involvement in UCE activities progresses from informing to consulting, involving, collaborating, and lastly, empowering the community. It may be in the form of service, outreach, partnership or curricular. Teichler (2017) uses the term socially responsible university to refer to the need for a university to be relevant to the society and that "university has to pay attention as well that it serves the generally agreed function of generating, preserving and disseminating knowledge appropriately". This paper share views of top management leaders on the current state of UCE initiatives and what needs to be done to create more impactful activities.
\end{abstract}

Keywords: socially responsible university, university-community engagement, policies on university-community engagement

\section{INTRODUCTION}

University-community engagement (UCE) is described by Carnegie Foundation for Advancement of Teaching (2012) as the collaboration between higher education institutions (HEIs) and their larger communities (local, regional or state, national, and global) for the mutually beneficial exchange of knowledge and resources in a context of partnership and reciprocity. UCE is meant to enrich scholarship, research, and creative activity; enhance curriculum, teaching, and learning; prepare educated, engaged citizens; strengthen democratic values and civic responsibility; address critical societal issues; and contribute to the public good (Carnegie Foundation for Advancement of Teaching, 2012). Thus, the community can leverage on the knowledge and expertise of the university to address the community's problems or needs while the university, through engagement initiatives, shape its research agenda and enhance student learning (Alter, 2005). Universities can also contribute to economic growth as well as help enhance the community's quality of life.

This study focused on four types of UCE activities: (i) service, (ii) outreach, (iii) partnership, and (iv) curricular (Carnegie Foundation for Advancement of Teaching, 2012). The types of engagement that were explored were confined to those that are scholarly in nature.

Service: Service refers to non-scholarly UCE activities such as building homes for the homeless.

Outreach: Outreach refers to the application and provision of institutional resources for community 
use with benefits to both the campus and the community

Partnership: Partnership refers to collaborative interaction with the community and to related scholarships for the mutually beneficial exchange, exploration, and application of knowledge, information, and resources.

Curricular: Curricular engagement described teaching, learning, and scholarship that engage faculty, students, and community in mutually beneficial and respectful collaboration.

On the other hand, involvement in UCE activities progresses from informing to consulting, involving, collaborating, and lastly, empowering the community. It is based on the model of engagement developed by the International Association for Public Participation (D'Ambrosio, 2011).

Informing: In informing, the university informs the community about a decision that has happened or about something that is going to happen and how to deal with it.

Consulting: Consultation involves negotiation for the purpose of obtaining feedback from the community about its needs.

Involving: Involving requires assisting the community in highlighting an issue to a higher authority.

Collaborating: Collaborating involves engaging with the community in decision-making, including searching for alternatives and the best solutions.

Empowering: Empowering refers to giving assistance to the community in governing their own problems as a result of engagement for mutual benefit.

\section{OBJECTIVES OF STUDY AND METHODOLOGY}

\subsection{Objectives of Study}

The research sought to access views of university's top management leaders on UCE and explores cultural and institutional barriers on scope and extent of involvement, recognition, impact and policies on UCE.

\subsection{Methodology}

Qualitative data collection consisted of semistructured interviews involving six Deputy Vice Chancellors (DVC) directly in charge of community engagement activities. The interviews covered topics relating to awareness; scope and extent of UCE activities, recognition given to UCE involvement, and impact of UCE on society and universities, and UCE strategies and policies.

\section{FINDINGS}

The discussion highlights emerging ideas, insights and themes that addressed the research questions. In some instances, cross-case comparisons were made to illuminate issues that are common to many institutions, and the similarities and differences across the universities.

\subsection{Academics' Level of Awareness}

The DVCs from the research universities believe that the level of awareness among their academics is high. They claimed that UCE activities are both widespread and varied. A DVC from a comprehensive university claimed that UCE is a new and a growing prominence of the purpose of universities and their third stream activities that fall outside the two core roles of teaching and research. The common theme in the third stream is externalising the work of the institutions and ensuring that they have wider intellectual, economic and social benefit. Community engagement was rationalised in terms of a sense of duty or responsibility. This sense of duty according to the DVCs emerged from the academics' perspectives on the value of higher education.

Interpretations and approaches to engagement also changed according to different university types. In the research universities, for example, engagement was viewed as a core feature not only of academics activities but as a means to conduct research or as a research methodology. The evidence thus suggest that community engagement and partnerships result in more 'cutting-edge' research projects and enhance the skill, quality and relevance of research. They provide opportunities for research to be conducted in an applied context that further increases the knowledge base of the academics involved.

It can be concluded that interviewees unanimously highlighted that the development of an engagement agenda should apply a vision and tradition of community engagement which firmly embeds engagement as a part of research and 
learning, which is explicitly rooted in academic knowledge.

\subsection{Scope of UCE}

The respondents revealed that the majority of their programs fell into the categories of education, economy and social services and mainly in the form of volunteer service. Some rely primarily on students volunteering service. However, students' community engagement is not equated with the pedagogy of service learning or community-based learning. Other scholarly activities include providing advice in decision making and policy, working with various ministries to develop curriculum, and sitting on advisory boards.

\subsection{Extent of UCE}

Engaging with the community should surpass consulting. Generally, the emphasis has been on developing a relationship with one or two organizations in their community and to collaborate in the activities. Some quoted activities with schools and disadvantaged groups within the local community, but the emphasis is on student volunteerism as a way of giving services. While some gave examples of activities that emphasise educational goals, aiming to help develop communities' skills. They were not sure whether the goal of empowerment was really achieved. Besides, many of the activities were merely short term projects. Therefore most of the activities only involves informing and consulting.

\subsection{Impact of UCE on Society/University}

The benefits of UCE are not always easily measured. Given the diverse approaches and strategies in increasing UCE, the respondents commonly stated that there are mechanisms in place to evaluate the success or effectiveness of their community engagement practices. Among the approaches used include survey feedback, exit feedback, impact survey, a set of criteria and Standard Operating Procedure and documentation.

It is clear that the evaluation procedure is aimed at the effectiveness of the activities rather than the actual impact of UCE. Formalised events were evaluated using basic feedback forms such as questionnaires. The continuation of collaborative efforts was deemed by most institutions as an indication of successful community engagement. At the time of the study, the universities surveyed seemed to focus efforts on classifying and counting to meet key performance indicators and they are still in the process of searching for effective generalizable metrics to measure impact.

\subsection{Recognition for UCE Work}

Regarding recognition for UCE involvement, a clear majority of the respondents discussed the inclusion of such involvement in their promotion criteria. This was seen by many as the main mechanism through which UCE could be formally rewarded at their universities. Admittedly, community engagement criteria is included in the yearly appraisal and promotion but the weightage given is small, between five to 10 per cent. The low weightage given for formal recognition was often cited as a barrier to place greater efforts toward UCE initiatives.

Overall, it was viewed that including UCE in promotions criteria would give recognition to those that do a lot of it but measurement of quality was not clearly mentioned by the respondents. The respondents' views indicate the complexity of this issue. Three main concerns with the promotion criteria emerged: what public engagement activities would be included; how quality as well as quantity of output would be measured; and, what fair weight need to be given to such activities in practice.

Interestingly, only one respondent highlighted the need to use an integrated view of faculty work, where what professors do as teachers, researchers, and service providers is viewed interdependently. Her view of faculty work is grounded in the scholarship of engagement, as a means to tie faculty disciplinary expertise to campus and community needs and to integrate the different aspects of faculty work. This particular university has recently increased the weight given to UCE contributions in annual performance appraisal to a maximum of $20 \%$ from $5 \%$.

However, it was discouraging to find no other examples of revised recognition and reward systems for evaluation and promotion that see service as a continuation of research and teaching. A standard response in the data was that institutions encouraged faculty to include community engagement scholarship in the service category, but that traditional scholarship (research and teaching scholarship) was the real requirement for promotion and tenure.

\subsection{Policies and Practices}

The findings show that the university policies have a substantial impact on UCE, mainly though their 
strategic plan which require students to complete a specific amount of community service (minimum of 2 credits) and make community engagement an agenda in decision making processes with respect to funding and academic role. Two respondents highlighted the importance of policies and an effective implementation system.

A top-down approach to cultivating engagement was seen to be preferable by the majority of the universities. This is aided by the creation of a position of Deputy Vice Chancellor for Industry and Community Partnership in 2010 at five national universities (four of those are research universities). This resulted in the creation of new university-wide office for industry-community partnership, coordinators and deputy deans in all faculties to systematically implement the policies and coordinate the practices. In all the universities, funding was seen as a determining factor in the frequency of engagement activity. The universities make use of the allocation for funding by the Ministry of Higher Education. Majority of the universities use the money to invest significantly in supporting the community engagement projects.

\section{CONCLUSIONS}

The research set out to explore the nature of and the factors affecting universities' engagement with their communities from the perspectives of university's top management leaders. More importantly, it aims to provide information that can help to improve and strengthen UCE. For the vast majority, community engagement is included in their mission statements. They support programs that are quite similar in nature and in the strategies that guide the conduct of volunteer services, applied research, community development projects with a more conscious attention to the social than economic impacts of their practices. They maintain staff offices that are responsible to organise and support the community engagement programs. Some institutions invest funds in supporting the programs but none invested in building and supporting the capabilities of their academics to carry out scholarly community engagement activities. The participating institutions have also demonstrated a spectrum of engagement at both the local and across border levels. The spread of experience in community engagement is evidently pragmatic. The evidence also shows that government policies have had a substantial impact on the institutions' community engagement policies and practices through transformation mandates and through incentives and research funding.
In summary, community engagement at the selected Malaysian higher learning institutions has been flourishing with good strategic institutional and government support. Nevertheless, there are numerous opportunities to stimulate greater levels of activity, in particular activities that focus on empowerment, to better coordinate existing activities and to develop and share best practices. The efforts to create universities that are more socially responsible (Teichler, 2017) should be intensified.

Developing a culture of scholarly UCE at the institutions where public engagement is a highly valued activity for academics and students is also vital. However, this requires time. Institutions are beginning to address some of the barriers to engagement, such as developing formal structures to recognise, support and reward UCE work and strategizing on how to sustain partnership for collaboration.

\section{ACKNOWLEDGEMENTS}

This research was funded by the Ministry of Higher Education Malaysia and supported by the National Higher Education Research Institute of Malaysia. We thank Dr Asyirah Abdul Rahim and Associate Professor Dr Munir Shuib from Universiti Sains Malaysia and Associate Professor Dr Tarmiji Masron of Universiti Malaysia Sarawak for their contribution to this study.

\section{REFERENCES}

Alter, T. (2005). Achieving the Promise of Public Scholarship. In S. Peters, N. Jordan, M. Adamek, T. Alter (eds.), "Engaging Campus and Community: the Practice of Public Scholarship in the State and LandGrant University System”, 461-487. Dayton, OH: Kettering Foundation.

Carnegie Foundation for the Advancement of Teaching. (2012). "Carnegie Elective Community Engagement Classification: First Time Classification Documentation Framework". Accessed on May 12, 2012 from http://classifications.carnegiefoundation.org/descripti ons/community_engagement.php

D'Ambrosio, J. (2011). Enabling engagement: A study of university-community engagement at a nonmetropolitan Australian university. Southern Cross University, Lismore, NSW: ePublication@SCU.

Teichler, U. (2017). The Socially Responsible University: Are we Moving Towards a WorldwideAccepted View? In M. Shuib \& Y. L. Koo, The Role of the University with a Focus on Universityu- 
Community Engagement, 14 - 37. Penang: Universiti Sains Malaysia Press. 